COLLECTING THEIR FAIR SHARE:

\title{
INFORMATION, VALUES, AND PUBLIC SUPPORT FOR THE INTERNAL REVENUE SERVICE
}

\author{
Ian G. Anson ${ }^{\mathrm{a}}$ \\ John V. Kane ${ }^{b}$
}

$2 / 7 / 2022$

Word count: 3,993

\begin{abstract}
In democracies, policy ambitions hinge upon governments' ability to collect tax revenue from their citizens. Ongoing funding cuts at the Internal Revenue Service (IRS) undermine the U.S. government's ability to fulfill this function. Yet, despite its central importance, funding for IRS enforcement activities has received scant scholarly attention, limiting our understanding of the factors that underlie public attitudes on this issue. In this article, we report the results of preregistered experiments that test whether citizens' attitudes regarding the IRS can be shaped by framing efforts. Specifically, we test both information-based and value-consistent frames that invoke partisans' core ideological concerns. Results show that these frames significantly increase public support for the IRS, as well as citizens' willingness to learn more and become politically active. Thus, to ensure state capacity, information about the consequences of IRS under-funding and appeals to partisans' ideological concerns can be implemented to increase support for tax collection.
\end{abstract}

Keywords: Framing, taxation, public support, IRS, ideology

a Department of Political Science, University of Maryland, Baltimore County, Baltimore, MD21250. ORCID ID\#: 0000-0002-1545-4270

${ }^{\mathrm{b}}$ Center for Global Affairs, New York University, New York, NY 10003. ORCID ID\#: 00000002-6720-8071 
In democracies, the policy ambitions of governments ultimately hinge upon the ability to collect tax revenue from citizens. The Internal Revenue Service (IRS) is the agency responsible for carrying out these tax collection activities in the United States. Each year, the IRS processes millions of individual and corporate tax returns, while also pursuing enforcement of the tax code through audits of those who underpay or fail to file a return.

However, IRS funding and staffing have both substantially decreased in recent years. This trend has been particularly acute in the realm of tax enforcement activities. While IRS funding for audits and other forms of tax enforcement reached a peak in 2010 of more than $\$ 6.5$ billion, the amount allocated to these tasks has declined by nearly a third over a ten-year period (Congressional Budget Office 2020). Staffing of enforcement activities has also witnessed a sharp decline, from a peak of around 51,000 employees in 2010 to fewer than 35,000 employees in 2018. These decreases weaken the ability of the IRS to effectively collect tax revenue from U.S. citizens (Kiel and Eisinger 2018).

A lack of tax code enforcement fundamentally threatens the United States' state capacity, or the ability of its government to accomplish policy goals (e.g., Besley and Persson 2009). Declining state capacity often yields negative consequences in countries that experience it, such as democratic backsliding, human rights abuses, and a lack of police enforcement of the law (Englehart 2009). As such, the subject of IRS enforcement funding has begun to enter more prominently into policy discussions, federal budgeting debates, and media attention (House Committee on the Budget 2020). Yet, despite the centrality of the IRS for ensuring U.S. state capacity, as well as the growing prominence of the IRS as a subject of policy debate, no research, to our knowledge, has sought to understand citizens' attitudes toward the IRS and, in particular, funding for IRS enforcement activities. National polls suggest that American support for the IRS 
in general tends to be lukewarm at best. A 2013 study, for example, found that support for the IRS was among the lowest of all federal agencies, with only $47 \%$ reporting a "favorable" or "mostly favorable" view of the agency (DeSilver 2013), while a more recent survey found 58\% of respondents giving the IRS a favorable rating (Pew Research Center 2018).

Our study is premised upon the notion that most citizens are unlikely to have strongly crystallized views on funding for IRS enforcement activities. For example, because it has only recently emerged as a focal point in policy circles, the average American is unlikely to have internalized cues about the IRS from elite political communicators. In a similar vein, the relatively narrow nature of IRS enforcement activity implies that citizens are unlikely to possess a great deal of information about this policy domain. For example, citizens may be unlikely to have considered the potential macro and politico-economic consequences of insufficient funding for IRS enforcement, and are likely unaware of the potential benefits of increased funding (e.g., a recent estimate finds that for every additional dollar the IRS spends on its tax enforcement activities, the U.S. government stands to gain $\$ 6$ in revenue; see Rampell 2021).

Previous research indicates that, with limited policy knowledge and little ability to rely upon cues from preferred elites, citizens can substantially change policy attitudes when presented with novel policy information (e.g., Bullock 2011). We therefore hypothesize that providing information about the consequences of underfunding IRS enforcement activities can affect citizens' attitudes toward IRS funding, their willingness to invest more time into learning about the topic, and even their willingness to become politically active on the issue.

H1. Exposure to information about the consequences of IRS underfunding is expected to increase Americans' willingness to support Internal Revenue Service enforcement activities relative to a control condition. 
While $\mathbf{H 1}$ is applicable to all Americans, it is nevertheless reasonable to expect substantial partisan differences in receptivity to such information. For example, existing polling finds a sizeable partisan gap in favorability toward the IRS in general, with only $50 \%$ of Republicans supportive of the agency, compared to 68\% of Democrats (Pew Research Center 2018). This implies that Republicans may be more resistant to simple informational frames about the IRS than Democrats. Thus, while framing has been shown to increase support for government agencies and their functions in the past (e.g., Nicholson and Howard 2003; Hvidman and Andersen 2016), for some citizens, attitudes towards the IRS may be more entrenched—especially among ideological opponents to taxation.

We therefore also explore whether, and to what extent, value-consistent frames are effective in changing partisans' policy attitudes and behavior regarding IRS funding. Value framing is a type of emphasis framing in which the idea-elements invoked by the frame speak to individuals' core values (Luong et al. 2019; Shen and Edwards 2005). If value frames resonate with the pre-existing ideological worldviews of audience members, they can powerfully reshape attitudes towards the issue under consideration. For example, DeMora et al.'s (2021) study evaluated the use of pro-masking frames targeted towards white evangelical Christians, finding that mask-wearing recommendations were most persuasive when accompanied by religious and partisan cues that appealed to core values.

For Republicans, we propose a frame that invokes the IRS' role in reducing the federal budget deficit through the enforcement of the tax code. In short, a logical consequence of enforcing the tax code is that, all else being equal, it will assist the U.S. government with minimizing deficit spending. This frame therefore explicitly invokes values related to fiscal conservatism and aversion to deficit spending, which should resonate favorably with Republicans. 
We also explore the effectiveness of a value-consistent frame for Democrats. The nature of the American tax code is progressive-i.e., income-inequality reducing — only to the extent that the IRS is able to enforce this code. In other words, without proper enforcement of the tax code, the redistributive effects of U.S. income tax policy are mitigated, particularly when there exists substantial tax avoidance at the top of the income distribution. We thus explore the possibility that highlighting the IRS's ability to reduce wealth inequality can change Democrats' attitudes and behavior beyond simple informational framing. Given the tendency for Democrats to identify fairness as a core concern (e.g., Jost et al. 2008), and their emphasis on equality specifically, a value-consistent frame of this nature is expected to further increase Democratic support for IRS funding. Based on this logic we propose $\mathbf{H 2}$ :

H2. Exposure to value-consistent frames is expected to increase partisans' willingness to support the Internal Revenue Service, relative to the receipt of information about IRS underfunding alone.

We acknowledge, though, that such value frames may not work symmetrically across parties. Republicans may not value deficit reduction to the same degree that Democrats value inequality reduction, or vice versa. Additionally, Republicans may have stronger attitudes about the IRS than Democrats, whether for ideological and/or recent historical reasons. For example, the IRS admitted that it had excessively scrutinized (conservative) Tea Party groups' applications for tax exempt status during the 2012 campaign season (Gurman 2017), leading to collections of large legal settlements from the IRS (see also Rappeport 2021).

In sum, while some literature has investigated the correlates of tax evasion and attitudes towards the tax system more broadly (e.g., Cowell 1992; Etzioni 1986; Mason et al. 2020), few scholars have investigated public support for the administration of tax policy. More specifically, 
public opinion research often studies perceptions of the fairness of the tax system, but has dedicated little attention to support for the operations of the IRS itself (e.g., Williamson 2017). By examining support for its enforcement activities, our study helps to advance our understanding of perceptions of the IRS as well as public support for a more nuanced conceptualization of government taxation (e.g., Yackee and Lowery 2005).

\section{METHODS AND DATA}

To test H1, we fielded a large pre-registered survey experiment on the Lucid Theorem platform from September 22-23, $2021(\mathrm{~N}=1,551) .{ }^{1}$ Lucid Theorem is a respondent marketplace that provides users with quota-based national samples that are demographically representative on characteristics such as age, sex, race and ethnicity, and region (see Coppock and McClellan 2019). Additional information about sample demographics and composition can be found in the Supplementary Information (SI) file.

The survey collected demographic information, including partisanship, prior to random assignment into one of four experimental conditions. Respondents were asked to read a brief passage about the IRS in every condition. In the Control condition, respondents read a brief

\footnotetext{
${ }^{1}$ This study's registration was written on June 8, 2021. We report no major discrepancies between the pre-registered analysis plan and the analysis described below. The pre-registration is available at: [Pre-registration link redacted for review. For a summary of this information, please see a For Peer Review Only section in the Supplementary Information which contains a reprint of the online registration.] The present study was declared Exempt by [Redacted Institution] Institutional Review Board on July 7, 2021 (Protocol \#2021-0675).
} 
statement describing the IRS and informing them that, "funding and staffing for the IRS has declined in recent years." In the Underfunding Frame, respondents saw this same message, in conjunction with an information-based statement concerning the consequences of underfunding IRS enforcement activities - specifically, the loss of government revenue.

The value-consistent experimental treatments include all text from the Control and Underfunding Frame conditions. However, the Deficit Reduction Frame also notes that "funding [the] IRS can reduce budget deficits." The Inequality Frame, alternatively, notes that funding the IRS can reduce economic inequality. See Table 1 for the verbatim text used in these vignettes. ${ }^{2}$

Our experimental design thus allows us to test the unique effects of both (1) information about the consequences of underfunding, as well as (2) value-consistent framing net of receiving information about underfunding. Specifically, observed differences between those assigned to the Underfunding Frame and the Control show the effects of information framing alone, while contrasts of the other frames against the Underfunding Frame identify the separate effects of valueconsistent framing.

We test the effects of these messages on three operationalizations of our key dependent variable of support for IRS enforcement activities (see the Supplementary Information for full question wording). Our first item is a measure of attitudinal support, that asks respondents whether Congress "should increase funding for the IRS' enforcement activities," measured on a sevenpoint Likert scale ranging from "strongly disagree" (1) to "strongly agree" (7).

\footnotetext{
${ }^{2}$ Our vignette text was informed by recent real-world discussions of tax enforcement (e.g., Rubin 2021).
} 


\section{TABLE 1. Experimental Vignette Wording}

\begin{tabular}{|c|c|}
\hline Condition & Vignette Text Assigned to Respondent \\
\hline Control & $\begin{array}{l}\text { The Internal Revenue Service (IRS) is the agency responsible for collecting tax dollars that } \\
\text { are legally owed to the federal government. It uses a variety of "enforcement activities"- } \\
\text { such as audits and collecting unpaid taxes - to accomplish this task. } \\
\text { According to a recent report from the Congressional Budget Office (CBO), funding and } \\
\text { staffing at the IRS has declined in recent years. }\end{array}$ \\
\hline $\begin{array}{l}\text { Underfunding } \\
\text { Frame }\end{array}$ & $\begin{array}{l}\text { [Control Message] }+ \\
\text { Many analysts worry that if funding for IRS enforcement activities remains too low, tax } \\
\text { dollars won't be collected properly. For example, the CBO estimates that the amount of } \\
\text { unpaid taxes between } 2011 \text { and } 2013 \text { averaged } \$ 381 \text { billion dollars per year. } \\
\text { The U.S. Treasury Department estimates that for every } \$ 1 \text { of additional funding to the IRS, } \\
\text { approximately } \$ 6 \text { of additional tax revenue could be collected. }\end{array}$ \\
\hline $\begin{array}{c}\text { Deficit } \\
\text { Reduction Frame }\end{array}$ & $\begin{array}{l}\text { [Control + Generic Frame Message] }+ \\
\text { FUNDING IRS CAN REDUCE BUDGET DEFICITS } \\
\text { Because tax dollars are used to fund federal government operations, unpaid taxes result in the } \\
\text { government spending more money than it takes in. When this happens, the government runs } \\
\text { a budget deficit. Analysts have determined that, by providing more funding for IRS } \\
\text { enforcement activities, it will help the federal government avoid large budget deficits, and } \\
\text { therefore help to reduce the national debt in the coming years. }\end{array}$ \\
\hline Inequality Frame & $\begin{array}{l}\text { [Control + Generic Frame Message] }+ \\
\text { FUNDING IRS CAN REDUCE ECONOMIC INEQUALITY } \\
\text { Because wealthy households receive forms of income that are easier to hide from the IRS, } \\
\text { such as income from business, extremely wealthy households are disproportionately } \\
\text { responsible for unpaid taxes. Analysts have determined that, by providing more funding for } \\
\text { IRS enforcement activities, it will help the federal government better enforce tax payments } \\
\text { from these extremely wealthy households, and therefore help to reduce economic } \\
\text { inequality in the coming years. }\end{array}$ \\
\hline
\end{tabular}


The next measures examine behavioral support. We asked respondents if after the survey, they would be "willing to receive an email containing more detailed information" about the benefits of funding the IRS, measured on a three-point scale ("yes," "unsure," or "no"). ${ }^{3}$ We also asked respondents if they would be "willing to either create or forward a brief message to [their] state's representatives in support" of IRS funding, also measured on the same three-point scale. Together, these questions provide us with a basis for understanding respondents' support for the IRS, as well as the strength of their convictions as they consider acting upon them.

We also included a series of manipulation checks designed to ensure that any differences in the treatment groups' responses occurred due to their exposure to the framing messages (e.g., Kane and Barabas 2019). These included a factual manipulation check, which found that respondents were more knowledgeable of the benefits of IRS funding in the treatment condition compared to the control condition, as well as a subjective manipulation check, which found that the Deficit Reduction and Inequality messages significantly affected, as intended, perceptions of the IRS's ability to reduce deficits and inequality, respectively, relative to the Underfunding message (see SI for more details).

Our analytical strategy relies primarily upon OLS regression to analyze the relevant treatment-control and treatment-treatment contrasts. ${ }^{4}$ To evaluate $\mathbf{H 1}$ and $\mathbf{H 2}$ we analyze three

\footnotetext{
${ }^{3}$ For ease of interpretation, we binarize this trichotomous scale by collapsing "unsure" and "no" responses. Results are robust to both specifications.

${ }^{4}$ Ordered Logistic models are fully robust to the models presented below, as seen in the Supplementary Information.
} 
experimental contrasts for each dependent variable: Underfunding Frame vs. Control; Deficit Reduction Frame vs. Underfunding Frame; and Inequality Frame vs. Underfunding Frame.

\section{RESULTS}

We first evaluate $\mathbf{H 1}$ by examining the effects of the Underfunding Frame on willingness to support the IRS relative to the Control condition. In Figure 1, below, we show that exposure to information about IRS underfunding substantially increases all respondents' willingness to provide both attitudinal and behavioral support for IRS enforcement. Specifically, informing respondents that underfunding will result in lost tax revenue increases respondents' attitudinal support by around 4 percentage points $(\mathrm{p}=0.07)$. This information also increases their willingness to learn more about the IRS by approximately 7 percentage points $(p<0.05)$, as well as their willingness to contact their representatives in support of the IRS by 7 percentage points $(p<0.05)$. Thus, consistent with H1, relative to the Control condition, informing citizens of the nature and consequences of IRS budget and staffing shortfalls stands to increase public support for funding IRS enforcement activities. 


\section{FIGURE 1. Effects of Underfunding Frame on Three Measures of Support for IRS}

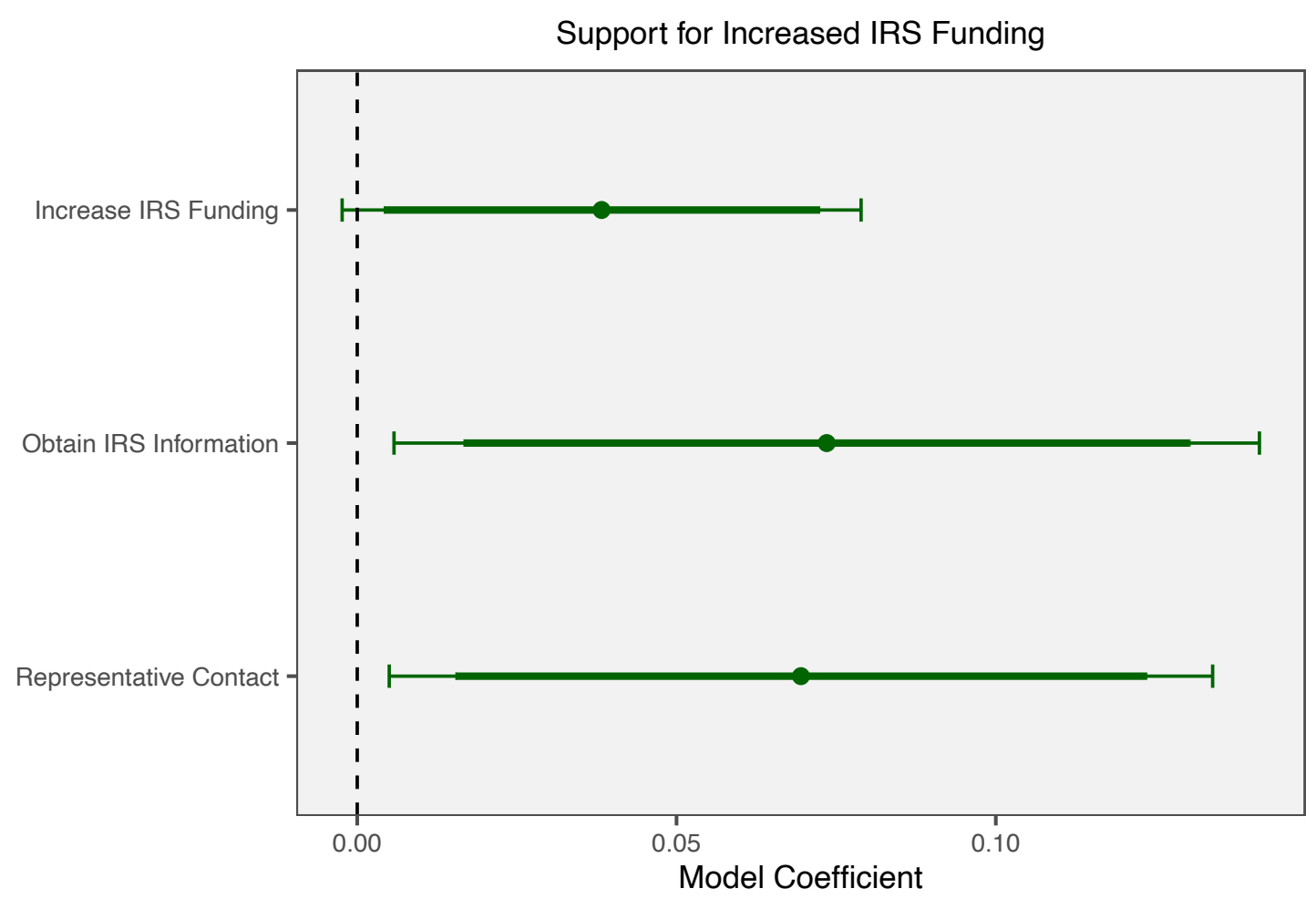

Notes: Thick horizontal lines denote $90 \%$ CIs; thin lines denote $95 \%$ CIs. Model coefficients based on results of OLS regression models predicting rescaled DVs with range [0,1]. Control group serves as the baseline for all estimates, represented by the dashed vertical line. $\mathrm{N}=778$.

To what extent were these findings homogeneous across partisan groups? Figure 2 displays the treatment effects, for all three outcome measures, across Republican and Democratic subgroups. The results here provide suggestive evidence that the Underfunding Frame has a stronger impact on Democratic respondents than Republicans. While the attitudinal measure is of similar magnitude for both subgroups, partisan asymmetry become more apparent on the behavioral measures: Democrats' increasing willingness to get information about the IRS ( $\delta=$ 13.2 percentage points, $\mathrm{p}<0.05)$, and willingness to contact their representatives $(\delta=11.9$ percentage points, $\mathrm{p}<0.05$ ) stands in marked contrast to Republicans' near-zero treatment effects. 
FIGURE 2. Effects of Underfunding Frame on Three Measures of Support for IRS by Party

Support for Increased IRS Funding by Party ID
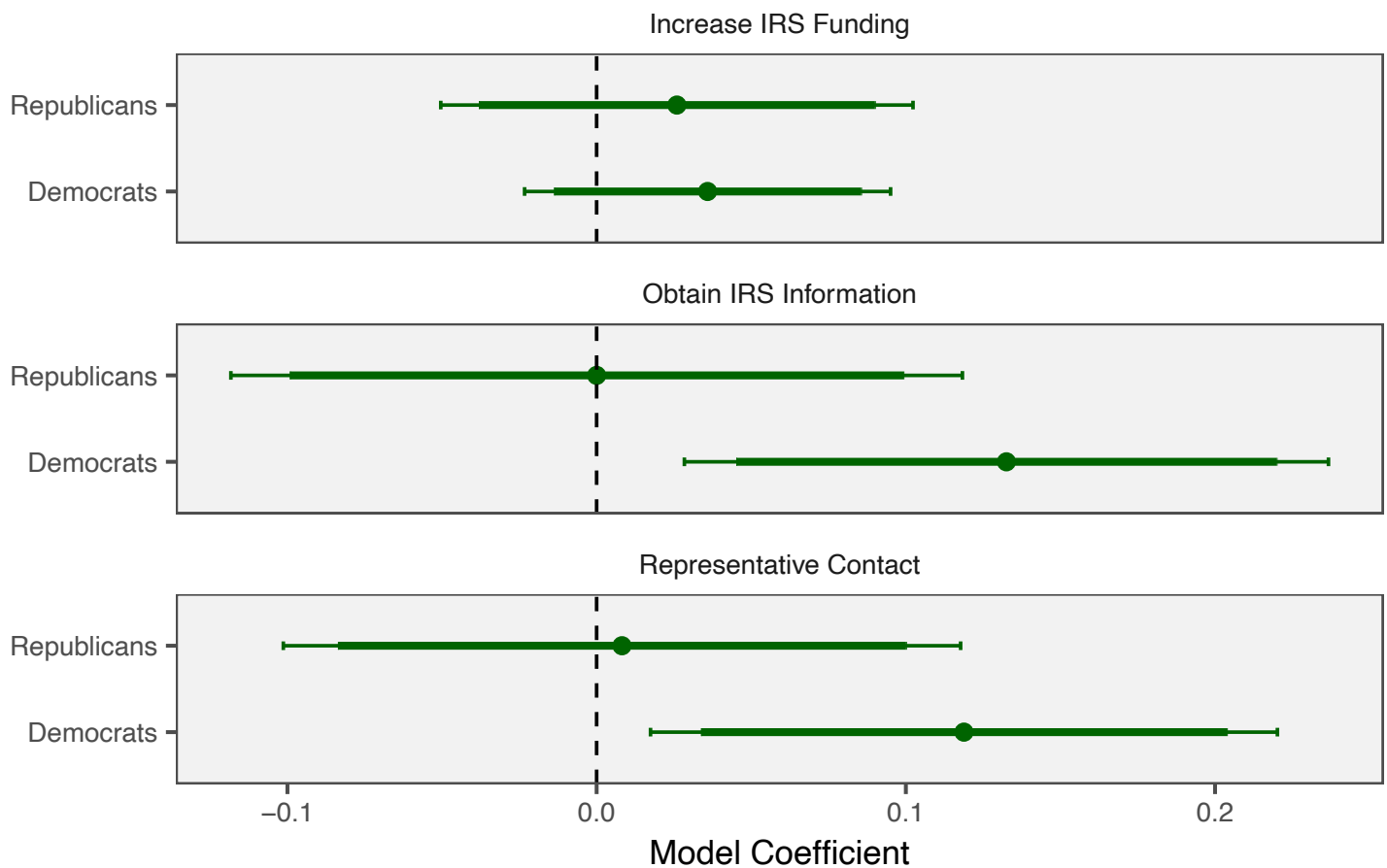

Notes: Thick horizontal lines denote $90 \%$ CIs; thin lines denote 95\% CIs. Model coefficients based on results of OLS regression models predicting rescaled DVs with range [0,1]. Control group serves as the baseline for all estimates. Democratic $\mathrm{N}=740$; Republican $\mathrm{N}=477.343$ Pure Independents excluded from results.

We therefore find noticeably stronger support for $\mathbf{H 1}$ among Democratic respondents than Republican respondents.

These asymmetric results across Democratic and Republican groups further motivate our next set of analyses, which examine the effects of value-consistent framing on support for the IRS (H2). Specifically, we examine whether, relative to the Underfunding Frame, messages cueing the IRS's ability to (1) reduce budget deficits, and (2) reduce economic inequality, significantly affect attitudinal and behavioral support for the IRS among Republicans and Democrats. 
FIGURE 3. Effects of Value-Consistent Frames on Three Measures of Support for IRS by Party
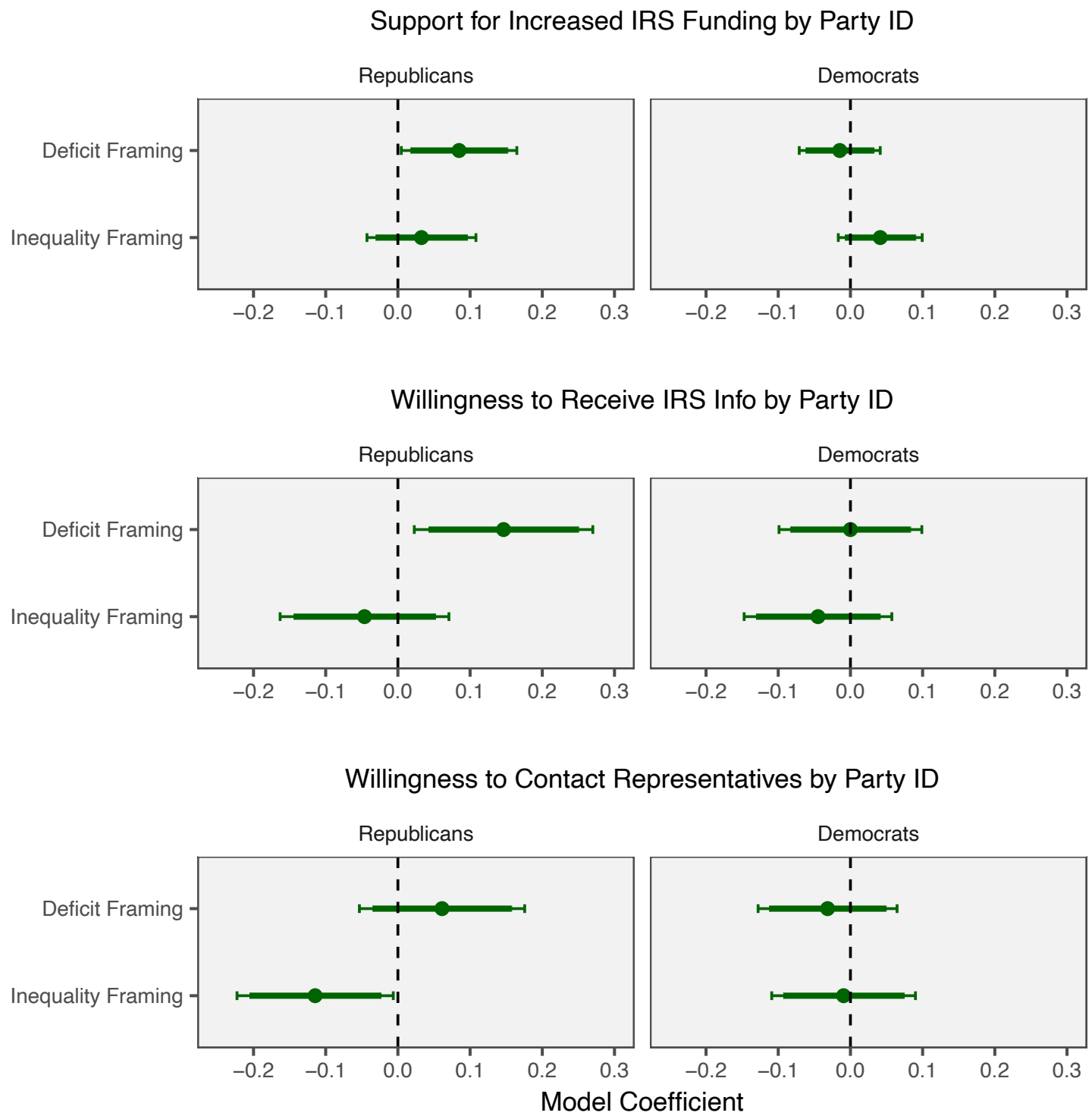

Notes: Thick horizontal lines denote $90 \%$ CIs; thin lines denote $95 \%$ CIs. Model coefficients based on results of OLS regression models predicting rescaled DVs with range [0,1]. Underfunding group serves as the baseline for all estimates, represented by the dashed vertical line. Democratic $\mathrm{N}=740$; Republican $\mathrm{N}=477.343$ Pure Independents excluded from results.

Figure 3 displays the effects of these value-consistent frames among both Republicans and Democrats, relative to the Underfunding Frame alone. Beginning with Republican respondents, the figure reveals that, in response to receiving a value-consistent message about the role of the IRS in reducing the federal budget deficit, Republicans increased their willingness to support the 
IRS by around 8.5 percentage points $(\mathrm{p}<0.05)$. In contrast, no significant increase in support for the IRS was found among Republicans assigned to the Inequality Frame relative to the Underfunding Frame $(\mathrm{p}=0.40)$. Further, Republicans exhibited a remarkable 14.6 percentage point increase in the probability of requesting more information about IRS activities $(\mathrm{p}<0.05)$, and a 6.1 percentage point increase in the probability of being willing to contact their representatives, although this latter result was not statistically significant ( $p=0.30$, two-tailed). Interestingly, Republicans reacted negatively to the Inequality Frame condition in these latter measures of IRS support, even becoming 11.4 percentage points less likely to seek out more information about the IRS $(\mathrm{p}<0.05)$.

The significant effects for value-consistent framing relative to an informational frame found among Republicans do not, however, tend to hold for Democrats. The effect of framing IRS enforcement activities as inequality-reducing on Democratic support for funding the IRS ( $\delta=4.1$, $p=0.16)$, likelihood of requesting more information $(\delta=-4.4, p=0.39)$, and likelihood of being willing to contact representatives $(\delta=-0.9, \mathrm{p}=0.85)$, were non-significant relative to the Underfunding Frame, though the former was nearly (marginally) significant and in the expected direction. Democrats also displayed no significant tendency to alter support for the IRS when the latter's enforcement activities were framed as being able to reduce the federal budget deficit.

In sum, for the average citizen, providing information about the consequences of underfunding the IRS appears to increase support for funding, desire to learn more information about the issue, and willingness to become more politically involved via contacting one's representatives in government. Among partisan citizens, however, information framing appears to be noticeably more efficacious among Democrats vis-à-vis Republicans, with Democrats exhibiting consistently positive effects and Republicans exhibiting far weaker, non-significant 
treatment effects. Once partisans were equipped with such information, however, we find that additional value-consistent framing (i.e., emphasizing the deficit-reducing or inequality-reducing potential of the IRS) tends to be more consequential for Republicans vis-à-vis Democrats, with Republicans exhibiting greater support for IRS funding, and greater willingness to learn more information, when told that funding the IRS's enforcement activities can potentially help to reduce federal budget deficits. ${ }^{5}$ While we cannot be certain as to why value-consistent frames were less efficacious for Democrats, it is potentially instructive to note that Democrats in the Control condition already exhibited greater support the IRS relative to Republicans, and the Underfunding Frame also had a stronger positive effect for Democrats than Republicans. When combined, these patterns suggest that the value-consistent frames may have been at greater risk of encountering a ceiling effect among Democrats relative to Republicans.

\section{DISCUSSION \& CONCLUSIONS}

Public support for tax collection agencies and the administration of the tax code remains an understudied topic in political science. Our study's results indicate that while information frames have the potential to increase public support for the IRS, by combining that information with value-consistent framing, communicators may be better able to increase public support for the IRS. Second, though framing research finds that message senders' identities can have powerful effects on the acceptance of new information, these results indicate that elites across the political spectrum may be more effective in increasing support for IRS enforcement activities (especially

\footnotetext{
${ }^{5}$ We find a similar pattern in the way partisans responded to the value-consistent frames in a pre-test conducted via Amazon MTurk in 2020, lending further support to these tentative conclusions (see the Supplementary Information).
} 
Republican identifiers) if they invoke considerations related to the federal budget deficit. While Democratic audiences may be more receptive to supporting the IRS in response to purely informational messages from trusted elites, Republican communicators should consider how to connect these messages to core conservative values.

While it is still unclear whether other messages designed to invoke core values can shift public attitudes towards the IRS, we reason that value-consistent framing of tax bureaucracy is likely broadly applicable a variety of country contexts. As tax collection agencies are scorned by rent-seeking elites in developing countries as well as industrialized democracies, we suggest that utilizing frames that invoke policy consequences and/or core political values may be an effective strategy that governments could employ to reestablish support for the very institutions that grant them their state capacity. 


\section{Works Cited}

Berry, Frances Stokes, and William D. Berry. 1992. "Tax innovation in the states: Capitalizing on political opportunity." American Journal of Political Science 36(3): 715-742.

Besley, Timothy, and Torsten Persson. 2009. "The origins of state capacity: Property rights, taxation, and politics." American Economic Review 99(4): 1218-44.

Bullock, John G. 2011. Elite influence on public opinion in an informed electorate. American Political Science Review, 105(3), 496-515.

Congressional Budget Office. 2020. Trends in the Internal Revenue Service's funding and enforcement. Technical Report, July 8. https://www.cbo.gov/publication/56422.

Coppock, A., \& McClellan, O. A. 2019. Validating the demographic, political, psychological, and experimental results obtained from a new source of online survey respondents. Research \& Politics, 6(1), 2053168018822174.

Cowell, F. A. (1992). Tax evasion and inequity. Journal of economic Psychology, 13(4), 521-543.

DeBot, Brandon, and Chuck Marr. 2015. "Poor IRS service reflects Congress' deep funding cuts." Center on Budget and Policy Priorities, June 1. https://www.cbpp.org/sites/default/files/atoms/files/6-1-15tax.pdf

DeMora, S. L., Merolla, J. L., Newman, B., \& Zechmeister, E. J. (2021). Reducing mask resistance among White evangelical Christians with value-consistent messages. Proceedings of the National Academy of Sciences, 118(21).

DeSilver, Drew. 2013. "IRS among least-popular federal agencies.” Pew Research Center, May 16. https://www.pewresearch.org/fact-tank/2013/05/16/irs-among-least-popular-federal-agencies/ 
Englehart, Neil A. 2009. "State capacity, state failure, and human rights." Journal of Peace Research 46(2): 163-180.

Etzioni, A. (1986). Tax evasion and perceptions of tax fairness: A research note. The Journal of Applied Behavioral Science, 22(2), 177-185.

Farhi, Paul. 2017. "Four years later, the IRS tea party scandal looks very different. It may not even be a scandal." The Washington Post, October 5. https:/www.washingtonpost.com/lifestyle/style/four-years-later-the-irs-tea-party-scandal-looksvery-different-it-may-not-even-be-a-scandal/2017/10/05/4e90c7ec-a9f7-11e7-850e2bdd1236be5d_story.html

Gurman, Sadie. 2017. "US agrees to pay tea party groups in suits over IRS scrutiny." The Associated Press, October 26. https://apnews.com/article/ff9f0798c7da44ecb59356b90296cd38

House Committee on the Budget. 2020. "Funding the IRS Pays Off: Preventing Tax Dodging by Wealthy Filers Is the First Step to Fixing Our Tax Code." Reports: $117^{\text {th }}$ Congress. October 1. https://budget.house.gov/publications/report/funding-irs.

Hunter, William J., and Michael A. Nelson. 1995. "Tax enforcement: A public choice perspective." Public Choice 82(1): 53-67.

Hvidman, Ulrik, and Simon Calmar Andersen. 2016. "Perceptions of public and private performance: Evidence from a survey experiment.” Public Administration Review 76(1): 111-120. Internal Revenue Service. 2021. "The Agency, its Mission and Statutory Authority." Irs.gov.

Jost, J. T., Nosek, B. A., \& Gosling, S. D. 2008. Ideology: Its resurgence in social, personality, and political psychology. Perspectives on Psychological Science, 3(2), 126-136. 
Kiel, Paul, and Jesse Eisinger. 2018. "How the IRS was gutted." ProPublica, December 11, https://www.propublica.org/article/how-the-irs-was-gutted

Luong, K. T., Garrett, R. K., \& Slater, M. D. (2019). Promoting persuasion with ideologically tailored science messages: A novel approach to research on emphasis framing. Science Communication, 41(4), 488-515.

Mason, Paul D., Steven Utke, and Brian M. Williams. 2020. "Why pay our fair share? How perceived influence over laws affects tax evasion." The Journal of the American Taxation Association 42(1): 133-156.

Nicholson, Stephen P., and Robert M. Howard. 2003. "Framing support for the Supreme Court in the aftermath of Bush v. Gore.” Journal of Politics 65(3): 676-695.

Pew Research Center. 2018. "Majorities Express Favorable Opinions of Several Federal Agencies, Including the FBI." Pew Research Center Report, February 14. https://www.pewresearch.org/politics/2018/02/14/majorities-express-favorable-opinions-ofseveral-federal-agencies-including-the-fbi/

Rampell, Catherine. 2021. "For every extra dollar invested in the IRS, the government could be getting \$6 back." The Washington Post, March 25. https://www.washingtonpost.com/opinions/want-to-shrink-deficits-or-fund-bidens-spendingplans-give-the-irs-more-money/2021/03/25/2959bcd8-8d90-11eb-942304079921c915_story.html

Romero, Jorge A. 2019. "Corporate lobbying and political contributions and their effects on tax avoidance." Journal of Public Affairs 19(2): e1923. 
Rubin, Richard. 2021. "High-Income Tax Avoidance Far Larger than Thought, New Paper Estimates." The Wall Street Journal, March 22. https://www.wsj.com/articles/high-income-taxavoidance-far-larger-than-thought-new-paper-estimates-11616364001

Scheufele, Dietram A. 1999. "Framing as a theory of media effects." Journal of communication 49(1): 103-122.

Shen, F., \& Edwards, H. H. (2005). Economic individualism, humanitarianism, and welfare reform: A value-based account of framing effects. Journal of Communication, 55(4), 795-809.

Williamson, V. S. (2017). Read my lips: Why Americans are proud to pay taxes. Princeton University Press.

Yackee, S. W., \& Lowery, D. (2005). Understanding public support for the US federal bureaucracy: A macro politics view. Public Management Review, 7(4), 515-536. 


\section{SUPPLEMENTARY INFORMATION:}

\section{COLLECTING THEIR FAIR SHARE: INFORMATION, VALUES, AND PUBLIC SUPPORT FOR THE INTERNAL REVENUE SERVICE}

\section{Table of Contents}

Experimental Sample Demographics and Information.......................................................... 2

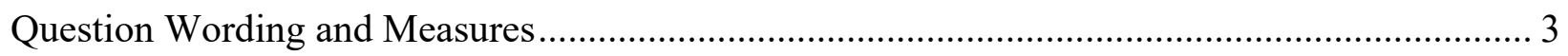

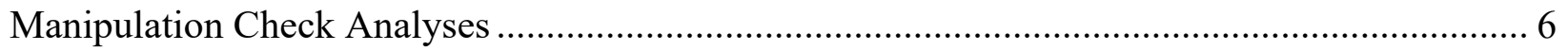

Tabular Regression Output \& Robustness Checks ……......................................................... 7

Results of Experimental Pre-Test ........................................................................................ 12

Pre-Registration Information, Data and Code Availability, and Ethics Statements ..................... 14 


\section{EXPERIMENTAL SAMPLE DEMOGRAPHICS AND INFORMATION}

The study was conducted on the Lucid Theorem platform from September 22-23, 2021. Respondents were recruited via the Lucid platform. This quota-based national sample is demographically representative to Census estimates for age, sex, race and ethnicity, and region. Randomization into experimental groups was performed using the Qualtrics platform, ensuring random assignment.

Below, Table S1 shows the demographic distribution of the sample.

Table S1. Descriptive Statistics, September 2021 Lucid Sample

\begin{tabular}{lcccccccc}
\hline \hline vars & $n$ & mean & sd & median & min & max & range & se \\
\hline Age & 1543 & 45.22 & 17.12 & 43 & 18 & 89 & 71 & 0.44 \\
Household Income & 1474 & 7.99 & 6.82 & 6 & 1 & 24 & 23 & 0.18 \\
Gender & 1543 & 1.50 & 0.50 & 2 & 1 & 2 & 1 & 0.01 \\
Ethnicity & 1543 & 2.68 & 4.10 & 1 & 1 & 16 & 15 & 0.10 \\
Hispanic & 1543 & 1.88 & 2.27 & 1 & 1 & 13 & 12 & 0.06 \\
Education & 1535 & 4.59 & 1.99 & 5 & 1 & 8 & 7 & 0.05 \\
PID (three-point) & 1559 & 1.83 & 0.87 & 2 & 1 & 3 & 3 & 0.02 \\
Region & 1543 & 2.64 & 1.05 & 3 & 1 & 4 & 3 & 0.03 \\
\hline
\end{tabular}




\section{QUESTION WORDING AND MEASURES}

Note: For experimental vignettes, please see Table 1 in the main text.

\section{Pre-Treatment Measures}

Generally speaking, do you consider yourself to be a(n):

- Strong Democrat

- Democrat

- Independent, but Leaning Democratic

- Independent

- Independent, but Leaning Republican

- Republican

- Strong Republican

Thinking about politics these days, how would you describe your own political viewpoint?

- Very Liberal

- Liberal

- Moderate

- Conservative

- Very Conservative

- Not Sure

In the past 7 days, about how many online surveys or polls (on any topic) have you completed? Please enter a whole number.

\section{Dependent Variable Measures}

The Internal Revenue Service (IRS) collects tax revenues that are lawfully owed to the federal government. It uses a variety of "enforcement activities"-such as audits and collecting unpaid 
taxes - to accomplish this goal. To what extent do you agree with the following statement: Congress should increase funding for the IRS's enforcement activities

- Strongly Disagree

- Disagree

- Slightly Disagree

- Neither Agree nor Disagree

- Slightly Agree

- Agree

- Strongly Agree

After the conclusion of the survey, would you be willing to receive an email containing more detailed information about the potential benefits of increased funding for IRS enforcement activities?

- Yes

- Unsure

- No

Policymakers in the federal government are currently considering whether or not to increase funding for IRS enforcement activities. Would you be willing to either create or forward a brief message to your state's representatives in support of increased funding for IRS enforcement activities?

- Yes

- Unsure

- No

\section{Experimental Manipulation Checks}

Please answer the following question to the best of your ability. According to U.S. Treasury Department estimates, for every $\$ 1$ of additional funding to the IRS, how much additional tax revenue would be collected?

- $\$ 0$

- $\$ 1$

- $\$ 6$

- $\$ 19$

- $\$ 27$ 
To the best of your knowledge, what has happened to IRS funding over the past ten years or so?

- IRS funding has fallen by a lot

- IRS funding has fallen slightly

- IRS funding has stayed about the same

- IRS funding has increased slightly

- IRS funding has increased a lot

To what extent would increased IRS funding help to reduce government deficits?

- Not at all

- Very little

- Somewhat

- A great deal

To what extent would increased funding for IRS enforcement activities help to reduce economic inequality?

- Not at all

- Very little

- Somewhat

- A great deal 


\section{MANIPULATION CHECK ANALYSES}

The results of OLS regression models predicting four manipulation checks show that the treatments significantly increased respondents' willingness to report responses in the correct direction. In Table S2 we show these results for the full sample. The first column indicates that the Underfunding Frame increased the likelihood of correctly answering that for every $\$ 1$ of additional IRS funding, $\$ 6$ of additional tax revenue would be collect (the increase in probability was slightly over 30 percentage points; $\mathrm{p}<.001$ ). The "IRS Reduces Deficits" column shows that, compared to the Control group, the Deficit Reduction frame did significantly increase the perception that increasing funding to the IRS "will help reduce government deficits" $(\mathrm{p}<.001)$. Finally, the "IRS Reduces Inequality" column shows that, compared to the Control group, the Inequality Reduction frame did significantly increase the perception that increasing funding to the IRS “will help reduce economic inequality" $(p<.001)$.

Table S2. Results of OLS Models Predicting Manipulation Check

\section{Dependent variable:}

\begin{tabular}{ccc}
\hline Factual MC: Correct & IRS Reduces & IRS Reduces \\
Response & Deficits & Inequality
\end{tabular}

Underfunding

Frame

$0.328^{* * *}$

Deficit Frame

$0.339^{* * *}$

$0.423^{* * *}$

(0.034)

(0.064)

Inequality Frame

$0.352^{* * *}$

$0.413^{* * *}$

Constant

$0.322^{* * *}$

$2.551^{* * *}$

$2.418^{* * *}$

(0.024)

(0.045)

Observations

1,551

769

775

Note:

${ }^{*} \mathrm{p}<0.1{ }^{* *} \mathrm{p}<0.05^{* * *} \mathrm{p}<0.01$ 
In Table S3 we show the effects of the manipulation checks for Republicans and Democrats separately. Results are consistent with those presented in Table S2, indicating that Republicans and Democrats' treatment effects were not a result of differential attention to the treatments.

Table S3. Results of Manipulation Checks by Partisan Group

\begin{tabular}{|c|c|c|c|c|c|c|}
\hline & \multicolumn{3}{|c|}{ Democrats } & \multicolumn{3}{|c|}{ Republicans } \\
\hline & $\begin{array}{l}\text { Factual } \\
\text { MC: } \\
\text { Correct }\end{array}$ & $\begin{array}{c}\text { IRS } \\
\text { Reduces } \\
\text { Deficits }\end{array}$ & $\begin{array}{c}\text { IRS Reduces } \\
\text { Inequality }\end{array}$ & $\begin{array}{c}\text { Factual MC: } \\
\text { Correct }\end{array}$ & $\begin{array}{c}\text { IRS } \\
\text { Reduces } \\
\text { Deficits }\end{array}$ & $\begin{array}{c}\text { IRS } \\
\text { Reduces } \\
\text { Inequality }\end{array}$ \\
\hline \multirow[t]{2}{*}{$\begin{array}{l}\text { Underfunding } \\
\text { Frame }\end{array}$} & $0.225^{* * *}$ & & & $0.459^{* * *}$ & & \\
\hline & $(0.052)$ & & & $(0.057)$ & & \\
\hline \multirow{3}{*}{$\begin{array}{l}\text { Deficit } \\
\text { Reduction } \\
\text { Frame }\end{array}$} & & & & & & \\
\hline & $0.271^{* * *}$ & $0.265^{* * *}$ & & $0.470^{* * *}$ & $0.605^{* * *}$ & \\
\hline & $(0.051)$ & $(0.092)$ & & $(0.060)$ & $(0.123)$ & \\
\hline \multirow[t]{2}{*}{$\begin{array}{l}\text { Inequality } \\
\text { Frame }\end{array}$} & $0.296^{* * *}$ & & $0.392^{* * *}$ & $0.473^{* * *}$ & & $0.527^{* * *}$ \\
\hline & $(0.052)$ & & $(0.099)$ & $(0.057)$ & & $(0.123)$ \\
\hline \multirow[t]{2}{*}{ Constant } & $0.361^{* * *}$ & $2.711^{* * *}$ & $2.608^{* * *}$ & $0.246^{* * *}$ & $2.385^{* * *}$ & $2.254^{* * *}$ \\
\hline & $(0.038)$ & $(0.068)$ & $(0.071)$ & $(0.041)$ & $(0.083)$ & $(0.088)$ \\
\hline Observations & 734 & 370 & 344 & 474 & 224 & 250 \\
\hline Note: & & & & \multicolumn{3}{|c|}{${ }^{*} \mathrm{p}<0.1^{* *} \mathrm{p}<0.05^{* * *} \mathrm{p}<0.0$} \\
\hline
\end{tabular}




\section{TABULAR REGRESSION OUTPUT \& ROBUSTNESS CHECKS}

Table S3. Tabular OLS Regression Results Corresponding to Manuscript Fig. 1

\begin{tabular}{|c|c|c|c|}
\hline & \multicolumn{3}{|c|}{ Dependent variable: } \\
\hline & IRS Support & Seek IRS Info. & Contact Reps. \\
\hline \multirow[t]{2}{*}{ Underfunding Frame } & $0.038^{*}$ & $0.074^{* *}$ & $0.069^{* *}$ \\
\hline & $(0.021)$ & $(0.035)$ & $(0.033)$ \\
\hline \multirow[t]{2}{*}{ Deficit Reduction Frame } & $0.068^{* * *}$ & $0.127^{* * *}$ & $0.096^{* * *}$ \\
\hline & $(0.021)$ & $(0.035)$ & $(0.033)$ \\
\hline \multirow[t]{2}{*}{ Inequality Frame } & $0.069^{* * *}$ & 0.037 & 0.033 \\
\hline & $(0.021)$ & $(0.035)$ & $(0.033)$ \\
\hline \multirow[t]{2}{*}{ Constant } & $0.516^{* * *}$ & $0.312^{* * *}$ & $0.252^{* * *}$ \\
\hline & $(0.015)$ & $(0.025)$ & $(0.023)$ \\
\hline Observations & 1,553 & 1,552 & 1,552 \\
\hline $\mathrm{R}^{2}$ & 0.009 & 0.009 & 0.006 \\
\hline Adjusted $\mathrm{R}^{2}$ & 0.008 & 0.007 & 0.004 \\
\hline Residual Std. Error & $0.289(\mathrm{df}=1549)$ & $0.481(\mathrm{df}=1548)$ & $0.458(\mathrm{df}=1548)$ \\
\hline F Statistic & \multicolumn{3}{|c|}{$4.920^{* * *}(\mathrm{df}=3 ; 1549) 4.897^{* * *}(\mathrm{df}=3 ; 1548) 3.251^{* *}(\mathrm{df}=3 ; 1548)$} \\
\hline
\end{tabular}


Table S4. Results of OLS Regression Corresponding to Manuscript Figs. 2 and 3

Dependent variable and Partisan Group:

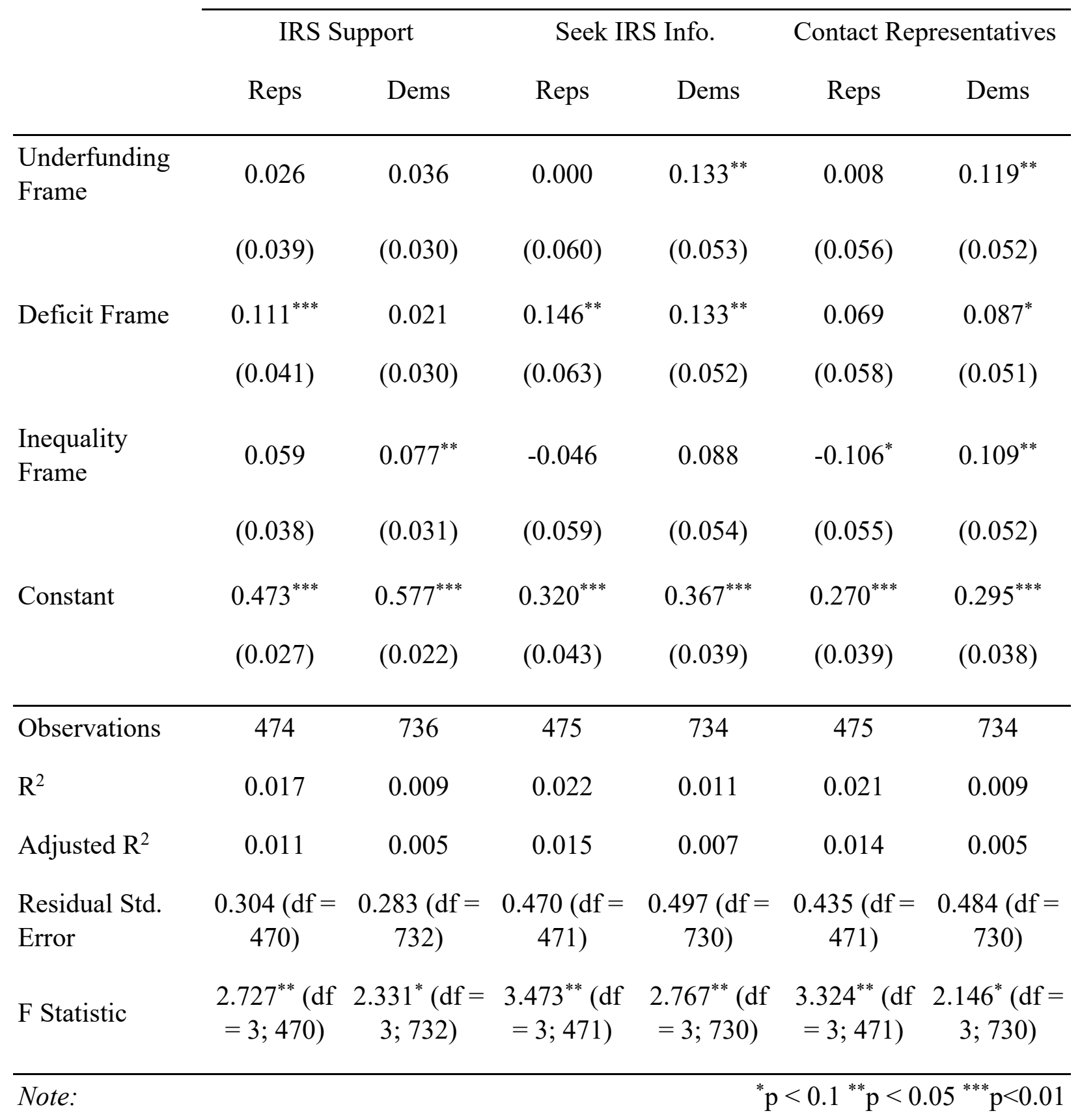


We note that for the two behavioral DVs, "Seek IRS Info" and "Contact Representatives," the study reduces a previously trichotomized variable to a binary variable. The decision to use OLS to model this new binary variable (relative to the harder-to-interpret logistic regression) has no substantive effect on the model outcome. Below, we also show that this decision has no effect on the substantive results for the Deficit Frame. While the results remain positively signed, the trichotomous variable yields less statistically significant findings for the Underfunding Frame.

Table S5. Alternative Model Specifications for Estimating Effects of Experimental Treatments on Willingness to Seek IRS Info. and Willingness to Contact Representatives

Dependent variable:

\begin{tabular}{lccccccc}
\hline $\begin{array}{l}\text { Seek } \\
\text { Info. }\end{array}$ & $\begin{array}{c}\text { Contact } \\
\text { Reps. }\end{array}$ & $\begin{array}{c}\text { Seek } \\
\text { Info. }\end{array}$ & $\begin{array}{c}\text { Contact } \\
\text { Reps. }\end{array}$ & $\begin{array}{c}\text { Seek Info } \\
\text { (trichot.) }\end{array}$ & $\begin{array}{c}\text { Contact } \\
\text { Reps. } \\
\text { (trichot.) }\end{array}$ & $\begin{array}{c}\text { Seek Info } \\
\text { (trichot.) }\end{array}$ & $\begin{array}{c}\text { Contact } \\
\text { Reps. } \\
\text { (trichot.) }\end{array}$ \\
OLS & OLS & logistic & logistic & OLS & OLS & ordered & ordered \\
& & & & & & logistic & logistic
\end{tabular}

\begin{tabular}{|c|c|c|c|c|c|c|c|c|}
\hline \multirow[t]{2}{*}{$\begin{array}{l}\text { Underfunding } \\
\text { Frame }\end{array}$} & $0.074^{* *}$ & $0.069^{* *}$ & $0.325^{* *}$ & $0.341^{* *}$ & 0.074 & 0.058 & 0.164 & 0.120 \\
\hline & $(0.035)$ & $(0.033)$ & $(0.151)$ & $(0.160)$ & $(0.060)$ & $(0.058)$ & $(0.131)$ & $(0.132)$ \\
\hline \multirow[t]{2}{*}{ Deficit Frame } & $0.127^{* * *}$ & $0.096^{* * *}$ & $0.547^{* * *}$ & $0.461^{* * *}$ & $0.161^{* * *}$ & $0.132^{* *}$ & $0.363^{* * *}$ & $0.292^{* *}$ \\
\hline & $(0.035)$ & $(0.033)$ & $(0.151)$ & $(0.159)$ & $(0.060)$ & $(0.058)$ & $(0.133)$ & $(0.132)$ \\
\hline \multirow[t]{2}{*}{$\begin{array}{l}\text { Inequality } \\
\text { Frame }\end{array}$} & 0.037 & 0.033 & 0.168 & 0.167 & 0.010 & 0.012 & 0.021 & 0.017 \\
\hline & $(0.035)$ & $(0.033)$ & $(0.153)$ & $(0.162)$ & $(0.060)$ & $(0.058)$ & $(0.131)$ & $(0.131)$ \\
\hline \multirow[t]{2}{*}{ Constant } & $0.312^{* * *}$ & $0.252^{* * *}$ & $-0.792^{* * *}$ & $-1.088^{* * *}$ & $1.018^{* * *}$ & $1.109^{* * *}$ & & \\
\hline & $(0.025)$ & $(0.023)$ & $(0.110)$ & $(0.117)$ & $(0.042)$ & $(0.041)$ & & \\
\hline Observations & 1,552 & 1,552 & 1,552 & 1,552 & 1,552 & 1,552 & 1,552 & 1,552 \\
\hline $\mathrm{R}^{2}$ & 0.009 & 0.006 & & & 0.006 & 0.004 & & \\
\hline Adjusted $\mathrm{R}^{2}$ & 0.007 & 0.004 & & & 0.004 & 0.002 & & \\
\hline
\end{tabular}


Log Likelihood

Akaike Inf. Crit.

Residual Std.

Error $(\mathrm{df}=$ 1548)

F Statistic $(\mathrm{df}=$

3; 1548)

Note:
$-1,016.34 \quad-945.203$

$2,040.679 \quad 1,898.406$

$0.481 \quad 0.458$

$0.834 \quad 0.811$

$3.046^{* *} \quad 2.120^{*}$ 


\section{Results of Experimental Pre-Test}

On August 2, 2021, an experimental pre-test was conducted via Amazon MTurk $(\mathrm{N}=358)$. The design of the study was similar to the study presented in the main text. The key differences are that this study featured a "pure control" (i.e., no information was shown to respondents) and the Control and Underfunding frames (detailed in the main text) were combined into one single "IRS Information" treatment vignette. The outcome measures are substantively identical to those in the main text. The results for value framing, while not always approaching statistical significance due to the small sample size, are consistent with the results presented in the main text.

Fig. S1 displays the effects of the "IRS Information" treatment on each of the three outcomes of interest in the study. We see that compared to the "pure" control, for some outcomes the treatment actually had a negative effect on IRS support. This was one reason why we were motivated to study the difference between the Control and Underfunding vignettes in the Lucid study presented in the main text.

Fig. S1. Effects of IRS Information Treatment vs. Pure Control on Three Measures of Support for IRS, August 2021 (Amazon MTurk Sample)

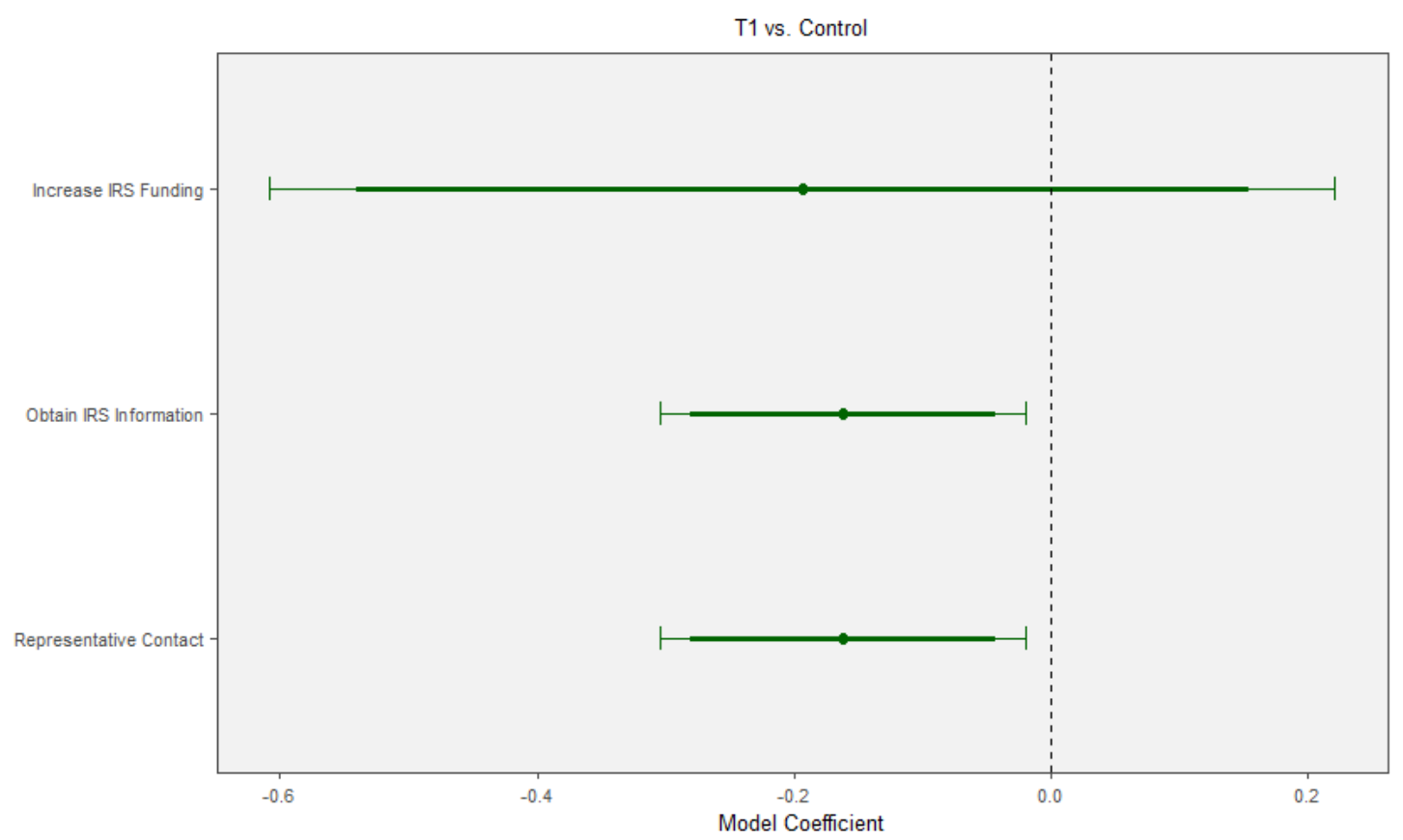

Notes: Increase Funding outcome is a seven-point scale (ranging from Strongly Disagree to Strongly Agree) rescaled to range from 0 to 1; Obtain Information and Contact Representative outcomes are trichotomous $(\mathrm{No}=0$, Unsure $=1$, Yes $=2$ ). OLS regression used for Increase Funding outcome; ordered logistic regression used for the two latter outcomes. Total $\mathrm{N}=358$. Thick horizontal lines indicate $90 \% \mathrm{CIs}$, thin horizontal lines indicate $95 \%$ CIs. 
Next, Table S7 shows the interaction between party and deficit- vs. inequality-reduction frames, an analysis that more clearly shows the effects of partisanship on reactions to value-consistent framing efforts, in line with what we found in the main text.

TABLE S7. Interactions Between Party and Deficit- vs. Inequality-Reduction Frames, Amazon MTurk Sample

\begin{tabular}{|c|c|c|c|}
\hline & $\begin{array}{l}\text { Increase } \\
\text { Funding }\end{array}$ & $\begin{array}{c}\text { Obtain } \\
\text { Information }\end{array}$ & $\begin{array}{c}\text { Contact } \\
\text { Representative }\end{array}$ \\
\hline \multirow[t]{2}{*}{$\begin{array}{l}\text { Inequality Frame (vs. Deficit Reduction } \\
\text { Frame) }\end{array}$} & 0.03 & -0.32 & 0.06 \\
\hline & $(0.04)$ & $(0.38)$ & $(0.35)$ \\
\hline Republican (vs. Democrat) & $\begin{array}{c}0.08 \\
(0.06)\end{array}$ & $\begin{array}{c}0.57 \\
(0.62)\end{array}$ & $\begin{array}{c}0.48 \\
(0.52)\end{array}$ \\
\hline Inequality Frame X Republican & $\begin{array}{l}-0.20^{*} \\
(0.08)\end{array}$ & $\begin{array}{l}-0.47 \\
(0.78)\end{array}$ & $\begin{array}{c}0.07 \\
(0.72)\end{array}$ \\
\hline Constant & $\begin{array}{l}0.72 * * * \\
(0.03)\end{array}$ & & \\
\hline Cut 1 & -- & $\begin{array}{l}-1.35 \\
(0.29)\end{array}$ & $\begin{array}{l}-0.90 \\
(0.26)\end{array}$ \\
\hline Cut 2 & -- & $\begin{array}{l}-0.70 \\
(0.27)\end{array}$ & $\begin{array}{l}-0.04 \\
(0.24)\end{array}$ \\
\hline $\begin{array}{l}\mathrm{N} \\
\mathrm{R}^{2}\end{array}$ & $\begin{array}{c}162 \\
0.04\end{array}$ & $\begin{array}{c}162 \\
.01\end{array}$ & $\begin{array}{c}162 \\
.01\end{array}$ \\
\hline $\begin{array}{l}\text { Notes: Increase Funding outcome is a se } \\
\text { Agree) rescaled to range from } 0 \text { to } 1 ; O b \\
\text { trichotomous }(\mathrm{No}=0 \text {, Unsure }=1 \text {, Yes }=2) \text {. } \\
\text { logistic regression used for the two latter out } \\
<0.05^{* *} \mathrm{p}<0.01^{* * *} \mathrm{p}<0.01 .\end{array}$ & $\begin{array}{l}\text { int scale }(\mathrm{r} \\
\text { nformation } \\
\text { egression } \mathrm{us} \\
\text { Total } \mathrm{N}=1\end{array}$ & $\begin{array}{l}\text { from Strongly } \\
\text { Intact Repres } \\
9 \text { Democrats ar }\end{array}$ & $\begin{array}{l}\text { isagree to Strongly } \\
\text { ative outcomes are } \\
\text { outcome; ordered } \\
43 \text { Republicans). }{ }^{*} \mathrm{p}\end{array}$ \\
\hline
\end{tabular}

Table S7 finds evidence that Republicans and Democrats responded significantly differently to the Deficit-reduction vs. Inequality-reduction frames in terms of their support for increasing IRS funding (see "Increase Funding" column). Republicans are significantly more willing to support the IRS after exposure to the Deficit Reduction frame relative to the Inequality Frame. Specifically, whereas moving from the Deficit-Reduction frame to the Inequality-Reduction frame predicts a slight, though non-significant increase in support among Democrats $(\beta=.03)$, it predicts a sharp decrease in support among Republican respondents. 


\section{PRE-REGISTRATION INFORMATION,}

\section{DATA AND CODE AVAILABILITY, \& ETHICS STATEMENTS}

Pre-registration for the present study was performed on the [redacted, see below] platform prior to all data collection. The pre-registration was performed after analysis was conducted on a small $(\mathrm{N}$ =350) pre-test on Amazon MTurk.

All data and code for the replication of the present study will be made available upon publication at the same [redacted] repository. Data will be made available in Stata .dta format and .csv format. $\mathrm{R}$ do-files will be made available which allow for the replication of graphical and tabular results.

All studies obtained Institutional Review Board (IRB) approval from the researchers' respective universities prior to fielding each survey. Each survey lasted approximately 8 minutes and concluded by thanking and debriefing respondents about the general purpose of the study. Respondents participated voluntarily and were compensated for their participation in an ethical manner, and in a way consistent with existing research practice (e.g., see Berinsky, Huber and Lenz 2012). Respondents in the Lucid study were paid $\$ 1$ for their participation (approximately $97 \%$ of the U.S. federal minimum wage (equal to $\$ 7.25$ at the time of our studies).

\section{Copv of Pre-Registration-For Peer Review Only}

Due to the potential for breached anonymity on the [redacted] platform, we provide a copy of the present study's pre-registration in print below. This copy is for peer review only and will be removed pending acceptance of the article.

\section{Study Information}

Hypotheses

Main Effects [T2] H1. Respondents reading vignettes about declining funding and staffing of the IRS [T2] are expected to exhibit increased support for funding the IRS compared to a control [T1]. H2. Respondents reading vignettes about declining funding and staffing of the IRS [T2] are expected to exhibit increased activism in support of the IRS compared to a control [T1]. Treatment-Specific Effects: T3 H3. A vignette containing a *budget deficit frame* in addition to information about declining IRS funding [T3] is expected to increase funding support for the IRS among Republicans H4. A vignette containing a *budget deficit frame* in addition to information about declining IRS funding [T3] is expected to increase activism in support for the IRS among Republicans Treatment-Specific Effects: T4 H5. A vignette containing an *inequality frame* in addition to information about declining IRS funding [T4] is expected to increase funding support for the IRS among Democrats, relative to a control [T1] H6. A vignette containing an *inequality frame* in addition to information about declining IRS funding [T4] is expected to increase activism in support for the IRS among Democrats, relative to a control [T1]

Design Plan

Study type 
Experiment - A researcher randomly assigns treatments to study subjects, this includes field or lab experiments. This is also known as an intervention experiment and includes randomized controlled trials. Blinding

- For studies that involve human subjects, they will not know the treatment group to which they have been assigned.

- Personnel who interact directly with the study subjects (either human or non-human subjects) will not be aware of the assigned treatments. (Commonly known as "double blind")

Is there any additional blinding in this study?

No response

Study design

Subjects are randomized into one of four experimental treatment groups. $\mathrm{T} 1$ is a pure control that gives respondents no additional information. $T 2$ asks respondents to read a vignette informing them of declining IRS funding and staffing. T3 asks respondents to read the T2 vignette and then read a statement containing information about the effects of IRS funding and staffing on budget deficits. T4 asks respondents to read the $\mathrm{T} 2$ vignette and then read a statement containing information about the effects of IRS funding and staffing on wealth inequality.

No files selected

Randomization

Simple randomization will be performed using the Qualtrics survey randomizer.

Sampling Plan

Existing Data

Registration prior to creation of data

Explanation of existing data

No existing data exist

Data collection procedures

Data will be collected using a Qualtrics survey distributed on the Lucid platform for research participant recruitment. Respondents will be paid in a manner that is commensurate with the minimum wage in Maryland based on the expected time to complete the study. Participants must be at least 18 years old and must reside in the United States.

No files selected

Sample size

Sample size is expected to be roughly 1000 participants.

Sample size rationale

We do not have a good power expectation, but our sample size is targeted based on funding availability and industry standards.

Stopping rule

$\mathrm{n} / \mathrm{a}$

Variables

Manipulated variables 
Please see the attached file for a description of the experimental treatment conditions.

Measured variables

Please see attachment

Indices

No indices will be used for analysis. We anticipate using the response option levels included in the survey as ordinal outcome variables.

No files selected

\section{Analysis Plan}

Statistical models

We will use linear regression (and replicate the results using ordinal logistic regression) to assess each hypothesis. Results will also be expressed visually using treatment mean estimates with $95 \%$ Confidence Interval error bars. For each hypothesis we anticipate specifying regression models with the following forms (expressed in R code snips): H1. Im(data=dat, IRS_Funding_Support as.factor(Treatment)) H2. Im(data=dat, IRS_Activism as.factor(Treatment)) H3 and H5. Im(data=dat, IRS_Funding_Support as.factor(Treatment) + as.factor(PID) + as.factor(Treatment)*as.factor(PID)) H4 and H6. Im(data=dat, IRS_Activism as.factor(Treatment) + as.factor(PID) + as.factor(Treatment)*as.factor(PID))

No files selected

Transformations

No response

Inference criteria

No response

Data exclusion

No response

Missing data

No response

Exploratory analysis

No response

Other

Other

No response 